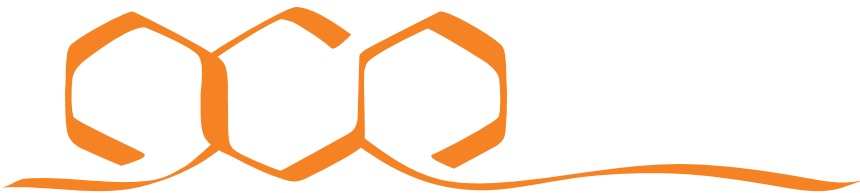 \\ COMMUNICATIONS CHEMISTRY
}

ARTICLE

https://doi.org/10.1038/s42004-019-0148-x OPEN

\section{Atomic structure observations and reaction dynamics simulations on triple phase boundaries in solid-oxide fuel cells}

\author{
Shu-Sheng Liu (10) 1,7, Leton C. Saha (10) 1,2,7, Albert Iskandarov (10 3 , Takayoshi Ishimoto ${ }^{1}$, Tomokazu Yamamoto ${ }^{4}$, \\ Yoshitaka Umeno ${ }^{3}$, Syo Matsumura ${ }^{1,4}$ \& Michihisa Koyama (10) $1,5,6$
}

The triple phase boundary (TPB) of metal, oxide, and gas phases in the anode of solid oxide fuel cells plays an important role in determining their performance. Here we explore the TPB structures from two aspects: atomic-resolution microscopy observation and reaction dynamics simulation. Experimentally, two distinct structures are found with different contact angles of metal/oxide interfaces, metal surfaces, and pore opening sizes, which have not previously been adopted in simulations. Reaction dynamics simulations are performed using realistic models for the hydrogen oxidation reaction (HOR) at the TPB, based on extensive development of reactive force field parameters. As a result, the activity of different structures towards HOR is clarified, and a higher activity is obtained on the TPB with smaller pore opening size. Three HOR pathways are identified: two types of hydrogen diffusion processes, and one type of oxygen migration process which is a new pathway.

\footnotetext{
${ }^{1}$ INAMORI Frontier Research Center, Kyushu University, 744 Motooka, Nishi-ku, Fukuoka 819-0395, Japan. ${ }^{2}$ Institute of Fluid Science, Tohoku University, 2 1-1 Katahira, Aoba-ku, Sendai 980-8577, Japan. ${ }^{3}$ Institute of Industrial Science, The University of Tokyo, 4-6-1 Komaba, Meguro-ku, Tokyo 153-8505, Japan.

${ }^{4}$ Department of Applied Quantum Physics and Nuclear Engineering, Kyushu University, 744 Motooka, Nishi-ku, Fukuoka 819-0395, Japan. ${ }^{5}$ Global Research Center for Environment and Energy based on Nanomaterials Science, National Institute for Materials Science, 1-1 Namiki, Tsukuba, Ibaraki 305-0044, Japan. ${ }^{6}$ Center for Energy and Environmental Science, Shinshu University, 4-17-1 Wakasato, Nagano, Nagano 380-8553, Japan. ${ }^{7}$ These authors contributed equally: Shu-Sheng Liu, Leton C. Saha. Correspondence and requests for materials should be addressed to S.-S.L. (email: shushengliu.001@gmail.com) or to L.C.S. (email: csleton@yahoo.com) or to M.K. (email: koyama.michihisa@nims.go.jp)
} 
A mong several types of fuel cells, the solid oxide fuel cell (SOFC) has the highest efficiency and could utilize various fuels ${ }^{1}$. The anode materials in SOFC are typically based on porous composites of $\mathrm{Ni}$ with oxides such as yttriastabilized zirconia (YSZ) or doped ceria ${ }^{1,2}$. Linking the complex porous structure to the cell performance is a critical issue for the development of SOFC. Realistic three-dimensional (3D) microstructures were obtained after the introduction of focused ion beam-scanning electron microscopy (FIB-SEM) technique to the field of SOFC ${ }^{3-6}$. Meanwhile, numerical modeling of porous electrode characteristics has been extended from twodimensional ${ }^{7,8}$ to $3 \mathrm{D}$ with the development of simulation methods, such as the lattice Boltzmann method ${ }^{8,9}$ and phase-field method ${ }^{10}$. Microscopically, the most important location related to the SOFC performance is the triple phase boundary (TPB), where the fuels are electrochemically oxidized ${ }^{11}$. The TPB structure and its local chemical environment determine the thermodynamics and kinetics of the electrochemical reaction.

Numerous works have been conducted to understand the local activity and reaction mechanism at the TPB. Patterned anodes were fabricated as ideal models to allow easy evaluation of the relationship between the TPB length and electrochemical characteristics $^{12-15}$ and to develop kinetic modeling methods ${ }^{14-19}$. However, both the experimental characteristics and modeling results show large variation among different reports ${ }^{20,21}$. For example, the current densities normalized by TPB length ${ }^{21}$ obtained by Bieberle et al. ${ }^{13}$ and Yao et al. ${ }^{15}$ are about three orders of magnitude higher compared to those by Mizusaki et al. ${ }^{12}$ while different rate-determining steps were reported, respectively, in those works including either $\mathrm{H}_{2}$ adsorption/desorption on Ni surface or removal of $\mathrm{O}^{2-}$ from the $\mathrm{YSZ}_{\text {surface }}{ }^{13}$, charge transfer reactions coupled with $\mathrm{H}_{2} \mathrm{O}$-related process ${ }^{15}$, and $\mathrm{Ni}$ surface hydrogen oxidation ${ }^{12}$. First-principles calculations were also applied to the TPB, nevertheless the deduced mechanism and estimated energy barriers differ significantly even when using similar structural models ${ }^{22-26}$. Recently, Liu et al. ${ }^{21}$ analyzed those deviations and pointed out the significant importance of elementary processes directly related to TPB at the atomic level. This encouraged us to trace the elementary reaction mechanism at TPB more carefully. Meanwhile, a reactive force field (ReaxFF) method has been developed to model the Ni/YSZ/ pore TPB and deduce the hydrogen oxidation mechanism ${ }^{27}$. However, the Ni surface amorphization and $\mathrm{Ni}$ decohesion from YSZ are observed at $1250 \mathrm{~K}$, which, we believe, may be due to a lack in the model stability or parameter reliability.

The TPB strongly affects the properties (including electrocatalysis) of various supported metal catalysts. Owing to their small sizes and easier handlings for observation, the atomic structures of TPB in nano-catalysts, such as $\mathrm{Ni} / \mathrm{MgAl}_{2} \mathrm{O}_{4}{ }^{28}, \mathrm{Pd} /$ $\mathrm{CeO}_{2}{ }^{29}, \mathrm{Pt} / \mathrm{SnO}_{2}{ }^{30}$, and $\mathrm{Au} / \gamma-\mathrm{Fe}_{2} \mathrm{O}_{3}{ }^{31}$ have been determined using transmission electron microscopy (TEM) or scanning TEM (STEM). In contrast, Ni/YSZ cermet in conventional SOFC is a bulk composite material whose particle size ranges from the submicrometer to micrometer. Its complex microstructure is challenging for the TEM specimen preparation ${ }^{32}$. Thus there has been no report on the atomic structure of TPBs in a practical cell, while significant experimental attention has been paid to the interfacial structures of Ni/YSZ ${ }^{33-37}$.

Considering the above-mentioned problems and difficulties in the atomic-scale researches on the TPB of SOFC, herein we report our experimental observations of realistic atomic TPB structures. In addition, we develop ReaxFF for TPB. Based on the obtained results, we computationally deduce the reaction mechanism therein. Two atomic structures of TPB, different from the models used in previous theoretical calculations, are introduced in this work. Overall, our reactive molecular dynamics (MD) simulations show that the hydrogen oxidation reaction (HOR) mechanism is notably influenced by the TPB models. Additionally, we find that the HOR can proceed through a newly discovered reaction pathway.

\section{Results}

TPB structure observation. In this work, the Ni/YSZ anode was fabricated through conventional processes ${ }^{38}$. For the microscopy observation, the pores in $\mathrm{Ni} / \mathrm{YSZ}$ were infiltrated with epoxy resin. The TEM specimens were extracted from the resinembedded bulk sample by the lift-out technique using an FIBSEM and thinned by gallium ion beam with a final voltage as low as $3 \mathrm{kV}$. In order to remove the damaged layers and the redeposition on the surfaces as much as possible, post-FIB processing was conducted using an Ar ion-milling machine with low voltages from 900 to $600 \mathrm{~V}^{39}$. Even after such mild procedure, some TPB areas were damaged by the ion beam because the sputtering rate of resin was higher than that of the anode materials.

Before showing the observed structures of TPB, we defined three angle parameters for the TPB. As shown in Supplementary Fig. $1, \theta_{\mathrm{Ni}}$, the so-called contact angle in metal/ceramic material, is the dihedral angle between the $\mathrm{Ni} /$ pore and $\mathrm{Ni} / \mathrm{YSZ}$ boundaries taking ceramic as the substrate. $\theta_{\mathrm{YSZ}}$ and $\theta_{\text {pore }}$ are defined in a similar way. Owing to the poor wettability between metallic $\mathrm{Ni}$ and ceramic YSZ, $\theta_{\mathrm{Ni}}$ was evaluated by Nelson et al. to be in the range of $140^{\circ}-155^{\circ}$, based on $3 \mathrm{D}$ reconstruction ${ }^{40}$. Large values of $\theta_{\mathrm{Ni}}$ were also observed in our sample (Supplementary Fig. 2). The value of $\theta_{\text {YSZ }}$ falls into two main cases if we restrict the spatial scale to several nanometers around the TPB. One is when YSZ acts as a flat substrate to the $\mathrm{Ni}$ particle $\left(\theta_{\mathrm{YSZ}}=180^{\circ}\right.$, Supplementary Fig. 1a), which corresponds to a small pore opening size $\left(\theta_{\text {pore }}\right)$ and is the dominant case in Supplementary Fig. 2. If the abovementioned statistical values of $\theta_{\mathrm{Ni}}$ are adopted ${ }^{40}, \theta_{\text {pore }}$ should be in the range of $25^{\circ}-40^{\circ}$. In the other case, YSZ does not extend in a straight way from the Ni/YSZ interface to the TPB area, and $\theta_{\mathrm{YSZ}}$ is much smaller than $180^{\circ}$ (Supplementary Fig. 1b), thereby a big pore opening size $\left(\theta_{\text {pore }}\right)$ is obtained with a value usually exceeding $90^{\circ}$ as pointed out by red arrows in Supplementary Fig. 2. Hereafter, these two TPB structures will be referred to as TPB-1 and TPB-2 types, respectively.

TPB-1 has a small $\theta_{\text {pore }}$ and one such example is indicated by the yellow arrow in Supplementary Fig. 2. The TEM observation was conducted in two directions of YSZ: the [013] and [001] zone axes, which have an included angle of $18.4^{\circ}$. The corresponding orientation relationships between $\mathrm{Ni}$ and $\mathrm{YSZ}$ are $\mathrm{Ni}[12 \overline{3}] / / \mathrm{YSZ}$ [013] (Supplementary Fig. 3) and Ni[110]//YSZ[001] (Supplementary Fig. 4), respectively. The abrupt Ni/YSZ and resin/YSZ interfaces were maintained after rotation (Fig. 1a, b), which indicates that they were always parallel to the observation directions. However, the $\mathrm{Ni} /$ resin interface (Ni surface) shows an apparent slope (marked by an arrow in Fig. 1a), which becomes abrupt in Fig. 1b. This phenomenon indicates that only the latter observation direction was parallel to the $\mathrm{Ni}$ surface. The contact angle between $\mathrm{Ni}$ and YSZ $\left(\theta_{\mathrm{Ni}}\right)$ was measured from Fig. $1 \mathrm{~b}$ to be $145^{\circ}$, which is in good agreement with the previously reported values ${ }^{40}$. Herein, $\theta_{\text {pore }}$ equals the supplementary angle of $\theta_{\mathrm{Ni}}$, namely $35^{\circ}$.

The high-resolution TEM (HRTEM) image at the YSZ[013] zone axis is shown in Fig. 1c. The YSZ(200) plane is exposed to the gas phase and in contact with the $\mathrm{Ni}(111)$ plane. Along the $\mathrm{Ni} / \mathrm{YSZ}$ interface, small steps could be detected that appeared blurred owing to the lattice overlap, as shown in Supplementary Fig. 5. The "steps" are where the Ni and YSZ are not perfectly parallel along the TEM observation direction or in the image plane. They are believed to be a part of the interfacial migration process that has been previously observed in $\mathrm{NiO} / \mathrm{YSZ}^{41}$ and $\mathrm{Ni} /$ 


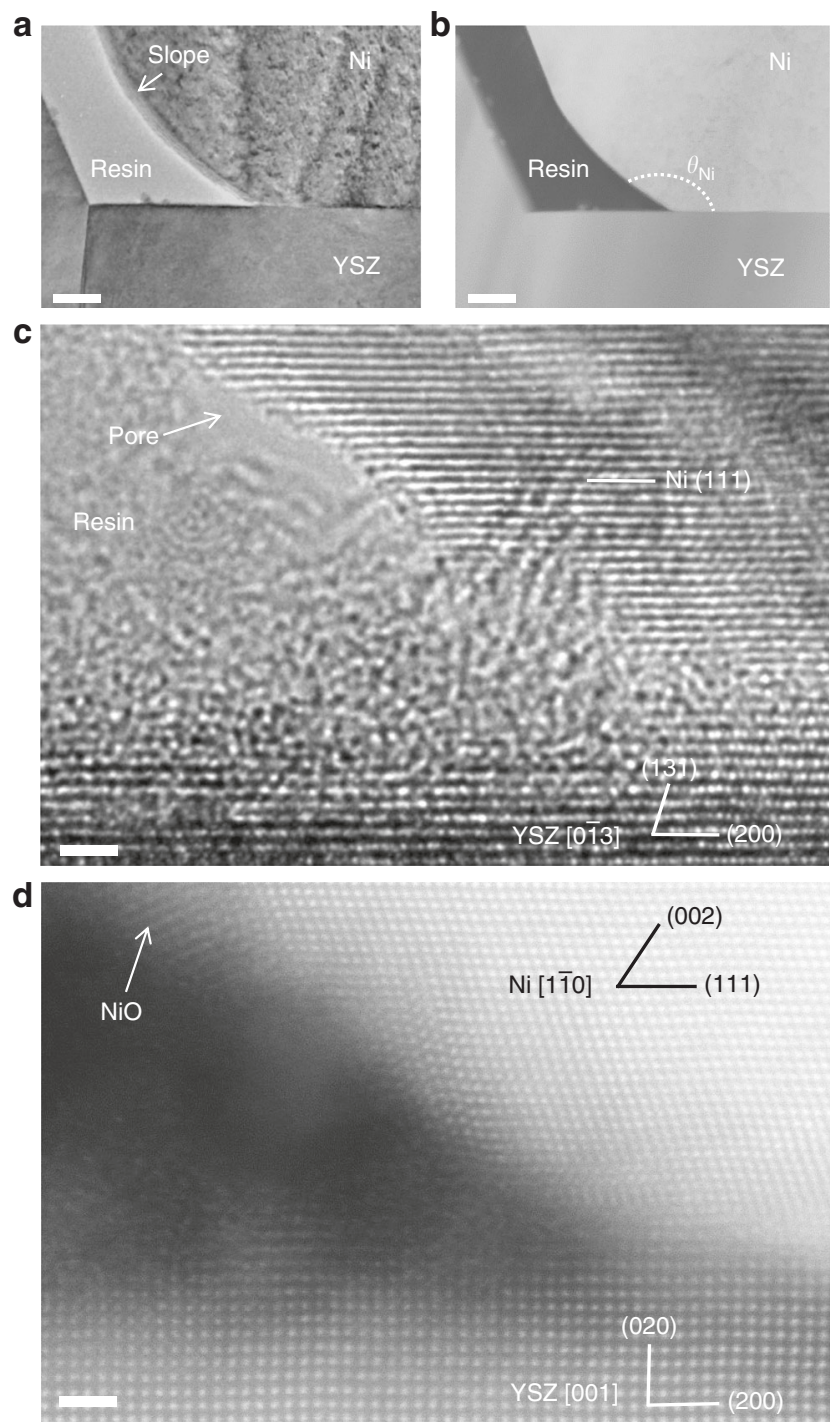

Fig. 1 Atomic structure of triple phase boundary-1. a Low-magnification transmission electron microscopy (TEM) image at YSZ[013] zone axis. The arrow in a points out the slope feature of $\mathrm{Ni}$ surface in this observation direction. b Low-magnification high-angle annular dark-field-scanning TEM (HAADF-STEM) image at YSZ[001] zone axis. The dash arc in $\mathbf{b}$ stands for the contact angle $\left(\theta_{\mathrm{Ni}}\right)$. c High-resolution TEM image at YSZ[013] zone axis. The arrow in $\mathbf{c}$ denotes a pore after electron beam damage of the resin. $\mathbf{d}$ HAADF-STEM image at YSZ[001] zone axis. The arrow in $\mathbf{d}$ points to a thin layer of $\mathrm{NiO}$ on the Ni surface. Scale bars in $\mathbf{a}, \mathbf{b}: 50 \mathrm{~nm}$; in $\mathbf{c}, \mathbf{d}: 1 \mathrm{~nm}$

$\mathrm{YSZ}^{42}$ as well as other metal-ceramic systems such as $\mathrm{Ag} / \mathrm{ZnO}^{43}$ and $\mathrm{Cu} / \mathrm{MgO}^{44}$. During the baking and reduction processes of $\mathrm{NiO} / \mathrm{YSZ}$, the interfacial layers of both $\mathrm{Ni}(\mathrm{O})$ and $\mathrm{YSZ}$ are expected to migrate due to many factors, such as thermal expansion, lattice shrinkage during reduction, lattice misfit, oxygen bonds change, etc. The migration of $\mathrm{Ni}, \mathrm{O}$, and $\mathrm{Zr}(\mathrm{Y})$ should proceed toward thermodynamic equilibrium. The interfacial distance between the contacting $\mathrm{Ni}$ and YSZ layers was measured to be $0.238 \mathrm{~nm}$ from the HRTEM image after background filtering (Supplementary Fig. 5). This value is intermediate to the lattice distances of $\mathrm{Ni}(111)$ and $\mathrm{YSZ}(200)$ planes and close to the reported value of $0.244 \mathrm{~nm}$ for a metal-metal (Ni-Zr) featured interconnection ${ }^{33}$ that was observed in a $\mathrm{Ni} / \mathrm{YSZ}$ specimen having the same orientation as
TPB-1 and prepared by the reduction/ion milling procedures similar to those adopted in the present study. Namely, the oxygen tends to be lost from the Ni/YSZ interface in TPB-1, and we attribute this to the $\mathrm{NiO}$ reduction process rather than the ion damage during FIB preparation. The final voltage adopted by us in FIB is $3 \mathrm{kV}$, which will cause a damage depth of around $5 \mathrm{~nm}$ if the milled material is silicon ${ }^{45}$. Furthermore, we adopted low voltage post-polishing by using Ar ion during the cooling with liquid nitrogen. This process removed most of the damaged layers on the specimen surfaces, especially the non-resin areas. All those procedures resulted in a damaged layer of merely $<3 \mathrm{~nm}$, judging from the Ni or YSZ surfaces in Fig. 1 and Supplementary Fig. 6. The specimen is estimated to have a thickness of about $70 \mathrm{~nm}$ near the $\mathrm{Ni}$ surface (resin) according to the geometrical parameters of the slope in Fig. 1a and the known angles. Therefore, the thin damaged layer on the surface will not change the whole structure of the specimen. Actually, O loss from the $\mathrm{Ni}$ / YSZ interface is not surprising because the anode was reduced under a $2 \%$ humidified hydrogen environment. Reportedly, O-Ni and $\mathrm{Zr}-\mathrm{Ni}$ bonds are energetically favorable ${ }^{35}$ and the $\mathrm{O}$ content at the interface may change with its partial pressure in the gas ${ }^{36}$ Thus the $\mathrm{O}$ content at the Ni/YSZ interface in TPB- 1 is expected to be augmented with increasing oxygen partial pressure in the atmosphere.

When the YSZ zone axis is changed to [001], the Ni surface can be indexed to (220) as shown in Fig. 1d. Actually, the dihedral angle between $\mathrm{Ni}(220)$ and $\mathrm{Ni}(111)$ planes in a single crystal is $35^{\circ}$, which is identical to $\theta_{\text {pore }}$ and confirms that the Ni surface facing the pore is the $\mathrm{Ni}(220)$ plane. Partial oxidation was found on the Ni surface (as pointed out by an arrow in Fig. 1d) but not at the TPB. Because of the damaged layers and thickness difference between the grain edges and bulk, the STEM contrast was weakened. We also found another region of interest with the same orientation and configuration as the one shown in Fig. 1d. In fact, its HRTEM image (Supplementary Fig. 6) exhibits the ion damage on the surfaces more clearly and supports the facet index. Therefore, we obtained the atomic structure near TPB, showing the $\mathrm{Ni}(220)$ and $\mathrm{YSZ}(200)$ surfaces to the pore at an interfacial orientation of $\mathrm{Ni}[1 \overline{1} 0] / / Y S Z[001]$ and $\mathrm{Ni}(111) / / \mathrm{YSZ}(200)$. The same oriented interfacial structure was observed in the Ni/YSZ samples prepared by directionally solidified eutectics ${ }^{33}$ and molecular beam epitaxy ${ }^{34}$. This is, in fact, one of the most stable interfaces found in $\mathrm{Ni} / \mathrm{YSZ}$ cermet $^{37}$.

Clear TEM images on TPB-2 were obtained from a specimen shown in Fig. 2 and Supplementary Fig. 7 with different magnifications. Apparently, this TPB has a larger $\theta_{\text {pore }}$ than that in TPB-1. An HRTEM image (Fig. 2b) was taken at the $\mathrm{Ni}[11 \overline{2}]$ zone axis. It was found that YSZ is close to the [001] zone axis, which can be seen more clearly from the diffraction patterns in Supplementary Fig. 7. The Ni(111) and YSZ(020) planes exposed to the resin (pore) and YSZ(200) planes act as one of the contact surfaces at the Ni/YSZ interface. $\theta_{\mathrm{Ni}}$ and $\theta_{\text {pore }}$ were measured to be $167^{\circ}$ and $103^{\circ}$ from the dihedral angles between $\mathrm{Ni}(111)$ and YSZ(200) and between $\mathrm{Ni}(111)$ and YSZ(020), respectively. Hence, $\theta_{\text {pore }}$ in TPB-2 is about two times larger than that in TPB-1. The $\mathrm{Ni}(2 \overline{2} 0)$ planes display a dihedral angle of $76.8^{\circ}$ to the $\mathrm{Ni} / Y S Z$ interface. These planes show a lattice misfit of merely $0.4 \%$, relative to the YSZ(020) plane, when taking into consideration that two layers of $\mathrm{Ni}(2 \overline{2} 0)$ planes match with one layer of YSZ(020) plane. Such a good match would stabilize the interface, although the contact surface of $\mathrm{Ni}$ phase was estimated to be a high-index (957) plane. Previously, we have reported other high-index interfaces that ubiquitously exist in the conventional $\mathrm{Ni} / Y S Z$ anode ${ }^{37}$. Later in this study, we will compare the structures of TPB-2 and TPB-1 in terms of their HOR activity. 

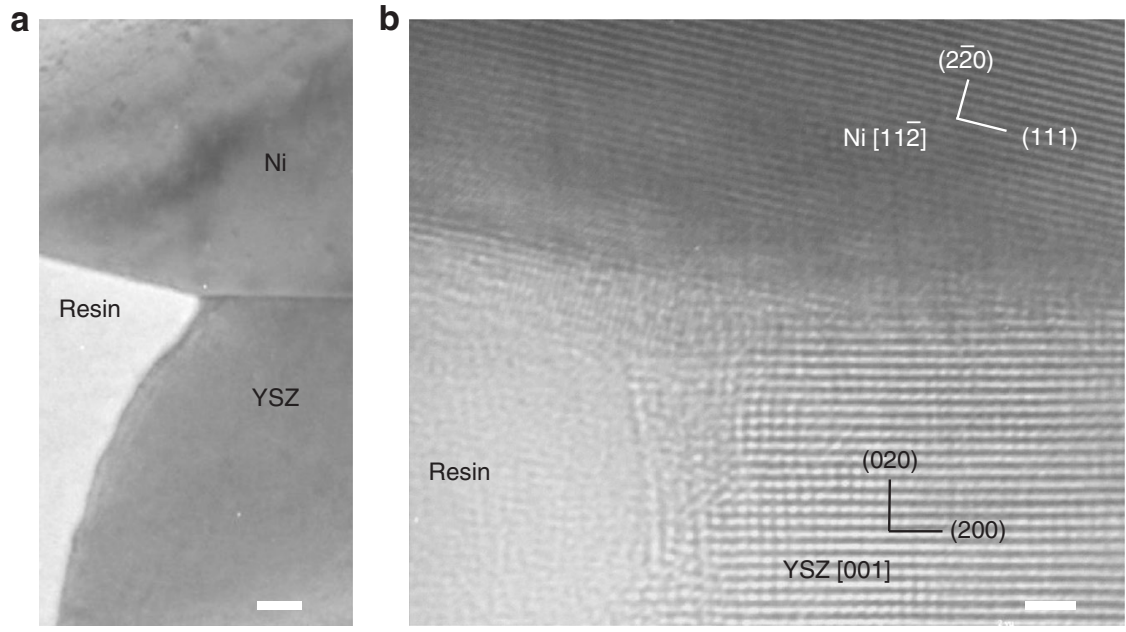

Fig. 2 Atomic structure of triple phase boundary-2. a Low-magnification transmission electron microscopy (TEM) image. b High-resolution TEM image at $\mathrm{Ni}[11 \overline{2}]$ zone axis. Scale bars in $\mathbf{a}, \mathbf{b}: 100$ and $1 \mathrm{~nm}$, respectively
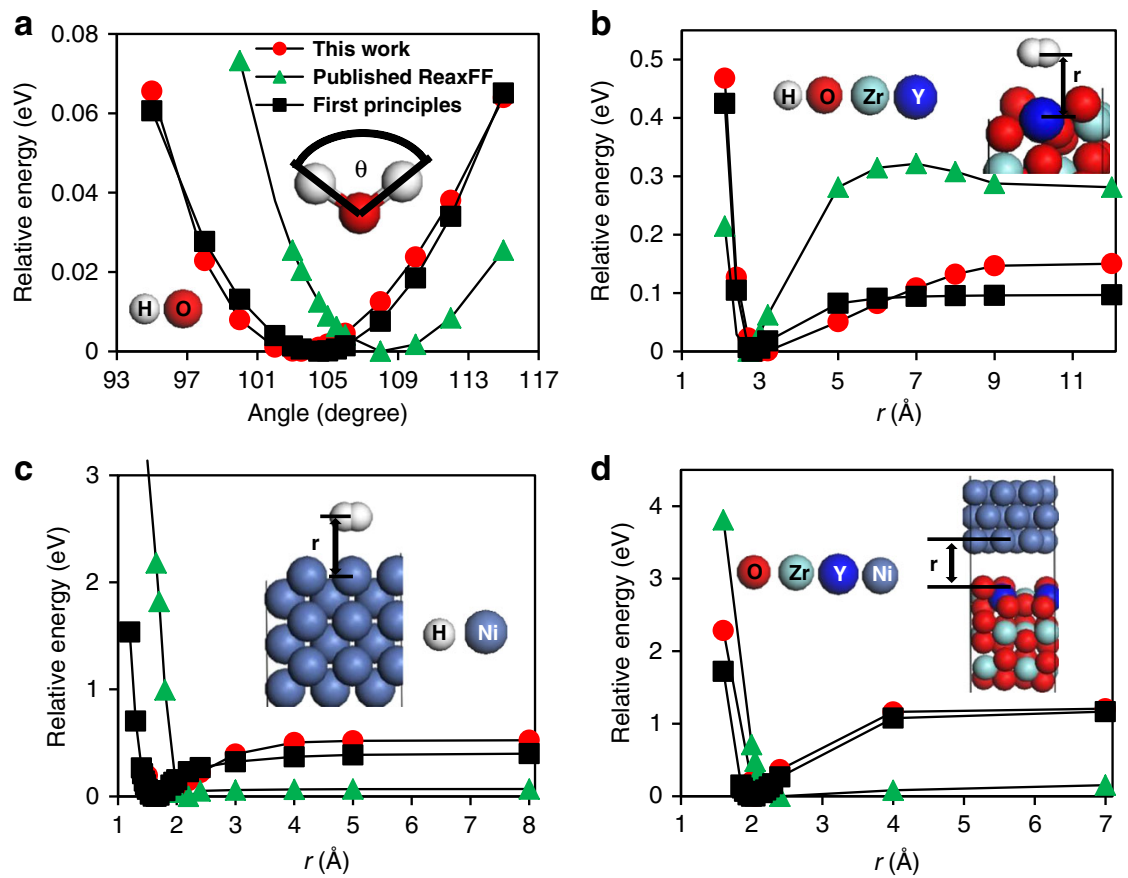

Fig. 3 Interaction energies and angle-energy curves. a H-O-H angle energy as a function of angle $(\theta)$. b YSZ(111) ( $\mathrm{Y}$-site)- $\mathrm{H}_{2}$ interaction energy. c Ni (220)- $\mathrm{H}_{2}$ interaction energy. d Ni(111)-YSZ(111) interaction energy. b-d are plotted as a function of distance ( $r$ ). The interaction energy and angle energy are expressed as relative to the equilibrium structure, through single-point energy calculations by changing $(r)$ and $(\theta)$. The insets show the models that are used for the energy calculation. Balls represent hydrogen $(\mathrm{H})$, oxygen $(\mathrm{O})$, zirconium ( $\mathrm{Zr}$ ), yttrium $(\mathrm{Y})$, and nickel (Ni) atoms. YSZ(111) slab with 3-layer $\mathrm{Zr} / \mathrm{Y}$ and 6-layer $\mathrm{O}$ is used in $\mathbf{b}$ and the entire structure is shown in $\mathbf{d}$

Force field development. In order to perform reliable calculation for the $\mathrm{Ni} / \mathrm{YSZ} / \mathrm{H}_{2}$ systems, we optimized the parameters adopted in the previously published ReaxFF descriptions of $\mathrm{Ni}$ and YSZ $^{27,46,47}$. POTFIT ${ }^{48}$ code, combined with LAMMPS ${ }^{49}$, was used to determine the new ReaxFF parameters for $\mathrm{H}-\mathrm{O}-\mathrm{H}, \mathrm{YSZ}-\mathrm{H}_{2}$, $\mathrm{Ni}-\mathrm{H}_{2}, \mathrm{Ni}-\mathrm{H}, \mathrm{Ni}-\mathrm{YSZ}$, and $\mathrm{O}-\mathrm{O}$ interactions, together with 24 additional energy values corresponding to the intermediate energy profiles of the HOR at TPB. The parameters were optimized to fit an extensive set of interaction energies in the $\mathrm{Ni} / \mathrm{YSZ} / \mathrm{H}_{2}$ systems, and the fitting results are shown in Fig. 3 and Supplementary Figs. 8-12. Figure $3 \mathrm{a}$ shows that the $\mathrm{H}-\mathrm{O}-\mathrm{H}$ equilibrium angle of the published ReaxFF has a deviation of about $4^{\circ}$ compared with that of the first-principles results, whereas our developed ReaxFF shows only $1^{\circ}$. For the published ReaxFF, the energy of nondissociative adsorption of $\mathrm{H}_{2}$ on YSZ(Y-site) is overestimated by $64 \%$ in comparison with the first-principles data (Fig. 3b), whereas the overestimation obtained with our developed ReaxFF is reduced to 33\%. Also, it is shown in Fig. 3c that the discrepancy of $0.6 \AA$ obtained for the equilibrium $\mathrm{Ni}-\mathrm{H}_{2}$ distance using the published ReaxFF has been eliminated with our ReaxFF. As shown in Fig. 3d, the magnitude of the interaction energy of Ni-YSZ interface at the equilibrium distance is underestimated by $86 \%$ with the published ReaxFF, while the underestimation is only $9 \%$ by using our ReaxFF. In summary, our developed ReaxFF parameters can reproduce the results of the first-principle calculations with much higher accuracy than the published ReaxFF ${ }^{27}$. More details on the way we evaluate the deviations between ReaxFF simulations and first-principles calculations can be found in Supplementary Notes 1, 
while the higher accuracy of the developed ReaxFF can be further proved by the comparison data in Table 1 and Supplementary Tables 1-11. In addition, the interactions of $\mathrm{H}-\mathrm{O}-\mathrm{H}, \mathrm{YSZ}-\mathrm{H}_{2}$, $\mathrm{Ni}-\mathrm{H}_{2}, \mathrm{Ni}-\mathrm{H}, \mathrm{Ni}-\mathrm{YSZ}$, and $\mathrm{O}-\mathrm{O}$ are described in Supplementary Notes 2-6 and the energies for the HOR are described in Supplementary Note 7.

TPB modeling and TEM image simulation. Based on the observed images, the initial atomic models were built in Material Studio by taking into account the actual lattice distances and crystal orientations. In an effort to validate the initial models, the QSTEM $^{50}$ software was used to simulate the TEM images by the multislice method. The observed and simulated images as well as the model for TPB-1 are shown in Fig. 4a, b, d. For TPB-1, there was a good agreement between the simulated (Fig. 4b) and observed (Fig. 4a) images, except for the possible thinning and damage of $\mathrm{Ni}$ and YSZ surfaces in Fig. 4a. To clarify the interfacial distance between Ni and YSZ, we superimposed the model on the experimental image in Fig. 4c. In the experimental image, it was difficult to determine the exact TPB region. Therefore, we constructed two more models by increasing the number of $\mathrm{Ni}$ layers toward the gas phase, resulting in different interfacial distances of $1.9,1.8$, and $1.7 \AA$ between $\mathrm{Ni}$ and $\mathrm{O}$ at the TPB region, hereafter referred to, respectively, as model-1 (Fig. 4 and Supplementary Fig. 13a), model-2 (Supplementary Fig. 13b), and

Table 1 Comparison of average deviations for ReaxFF

\begin{tabular}{llll} 
ReaxFF & MADa & MSD $^{\mathbf{b}}$ & STD $^{\mathbf{c}}$ \\
\hline Published $(\mathrm{eV})$ & 0.59 & 1.00 & 0.81 \\
This work $(\mathrm{eV})$ & 0.18 & 0.17 & 0.37 \\
\hline
\end{tabular}

Each deviation was calculated by the collections of $24 \mathrm{HOR}$ energies and the interaction energies of $\mathrm{H}-\mathrm{O}-\mathrm{H}, \mathrm{YSZ}$ (three sites) $-\mathrm{H}_{2}, \mathrm{Ni}-\mathrm{H}_{2}, \mathrm{Ni}-\mathrm{H}, \mathrm{Ni}-\mathrm{YSZ}$, and O-O

ReaxFF reactive force field

a Mean absolute deviation $(M A D)=\frac{\sum\left|E_{\text {Rearf }}-E_{\text {FP }}\right|}{n}$

bMean square deviation $(M S D)=\frac{\sum\left(\left|E_{\text {ReaxfF }}-E_{F P}\right|\right)^{2}}{n}$

cStandard deviation $(S T D)=\sqrt{\frac{\sum\left(\left(\left|E_{\text {Rexpf }}-E_{F p}\right|\right)-(M A D)^{2}\right)}{n}}$

where $E_{\mathrm{FP}}$ and $E_{\text {ReaxFF }}$ are the energies obtained from first-principles calculations and ReaxFF simulations, respectively, and $n$ is the number of data points model-3 (Supplementary Fig. 13c). The model of TPB-2 will be illustrated in a later section.

Reaction dynamics. Before simulating the reaction dynamics, we optimized the structures of TPB-1 by adding hydrogen $(\mathrm{H})$ atoms at randomly selected atop sites of $\mathrm{Ni}$ surfaces. To investigate the hydrogen oxidation process, we prepared the model with adsorbed $\mathrm{H}$ assuming that the adsorption is sufficiently fast and is in equilibrium. The surface coverage of $\mathrm{H}$ is predicted to be $7 \%$, which is the maximum coverage under the conditions of $1073 \mathrm{~K}$ and $1 \mathrm{~atm}$ with $100 \% \mathrm{H}_{2}$ following the reported calculation method $^{51}$. After the optimization, $\mathrm{H}$ atom on the $\mathrm{Ni}(220)$ surface is found to be at the long bridge site.

For model-1, a single pathway was observed during the simulation as shown in Fig. 5a. In particular, $\mathrm{H}$ moved on the $\mathrm{Ni}$ (220) surface to react with $\mathrm{O}$ at the TPB site, resulting in the formation of $\mathrm{OH}$ (see the series of snapshots in Supplementary Fig. 14). This pathway is noted herein as HOR-I, which was reported by Vogler et al. ${ }^{18}$ using kinetic modeling and defined as an $\mathrm{H}$ spillover process. Subsequently, in their density functional theory (DFT) calculations Shishikin et al. ${ }^{22}$, Cucinotta et al. ${ }^{23}$, and Liu et al. ${ }^{26}$ concluded that the $\mathrm{H}$ spillover process is the most favorable pathway. Liu et al. also found that the reaction barrier of this process varies from 0.46 to $0.57 \mathrm{eV}$ depending on the local structures of TPB sites. This process was also identified by employing ReaxFF-MD simulations ${ }^{27}$. For our simulation, a total of $3 \mathrm{OH}$ species were formed after $700 \mathrm{ps}$. One of them moved to the YSZ surface near TPB with the distances of 2.7 and $2.1 \AA$ from the nearest $\mathrm{Ni}$ and $\mathrm{Zr}$ atoms, respectively. The other two $\mathrm{OH}$ species gradually moved toward the $\mathrm{Ni}(220)$ surface sites, which was specified as the $\mathrm{OH}$ spillover or back-transfer in the kinetic study by Goodwin et al. ${ }^{19}$. In contrast, the $\mathrm{OH}$ spillover process was not favorable according to the above-mentioned DFT calculations $22,23,26$, while it was not perceived in the ReaxFFMD simulations ${ }^{27}$.

Two other HOR pathways were observed on model-2 during the simulation. One pathway is dominated by $\mathrm{H}$ atom incorporation into the interstitial site of the $\mathrm{Ni}$ lattice and diffusion to the interface between $\mathrm{Ni}$ and YSZ. In this case, $\mathrm{H}$ eventually combines with $\mathrm{O}$ at the $\mathrm{Ni} / \mathrm{YSZ}$ interface to form $\mathrm{OH}$.
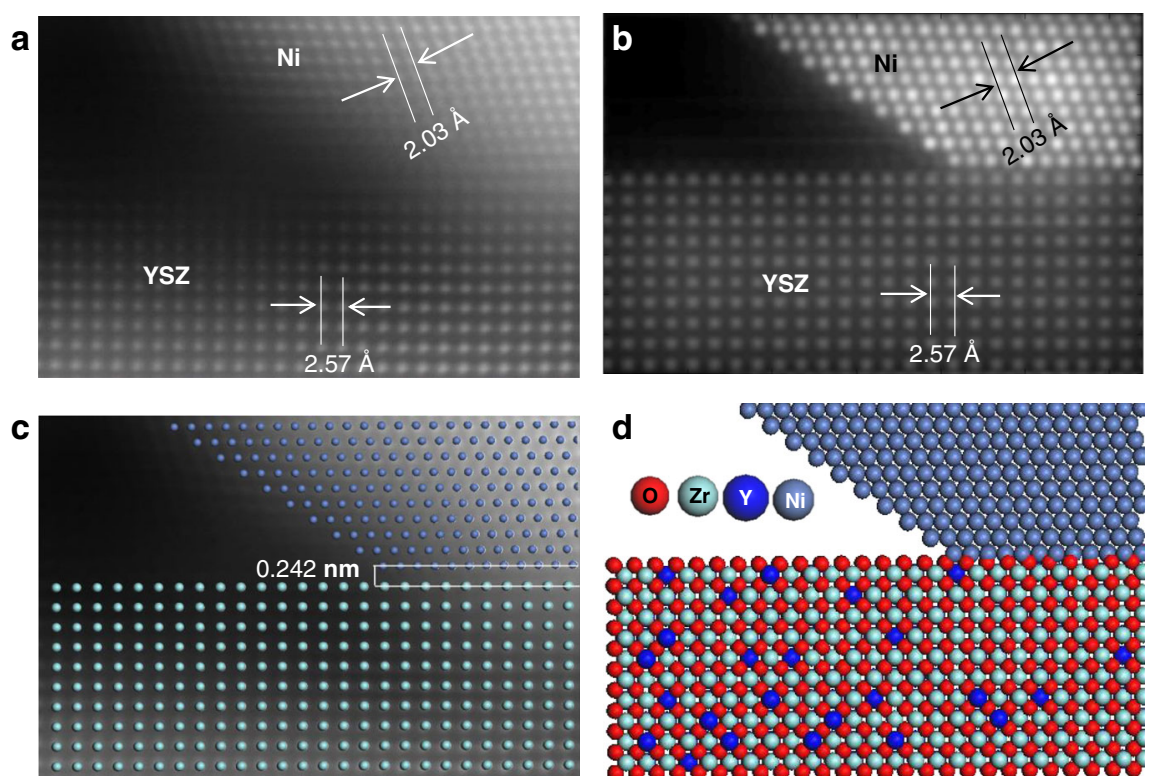

Fig. 4 Model structures of triple phase boundary-1. a Experimental image. b Simulated image by using the QSTEM software. c Atomistic model imposed on the experimental image. d Atomistic model containing $\mathrm{Ni}$ (1770 atoms) and $\mathrm{YSZ}\left(\mathrm{Zr}_{1100} \mathrm{Y}_{200} \mathrm{O}_{2500}, 8 \mathrm{~mol} \%\right.$ of yttria) 
a
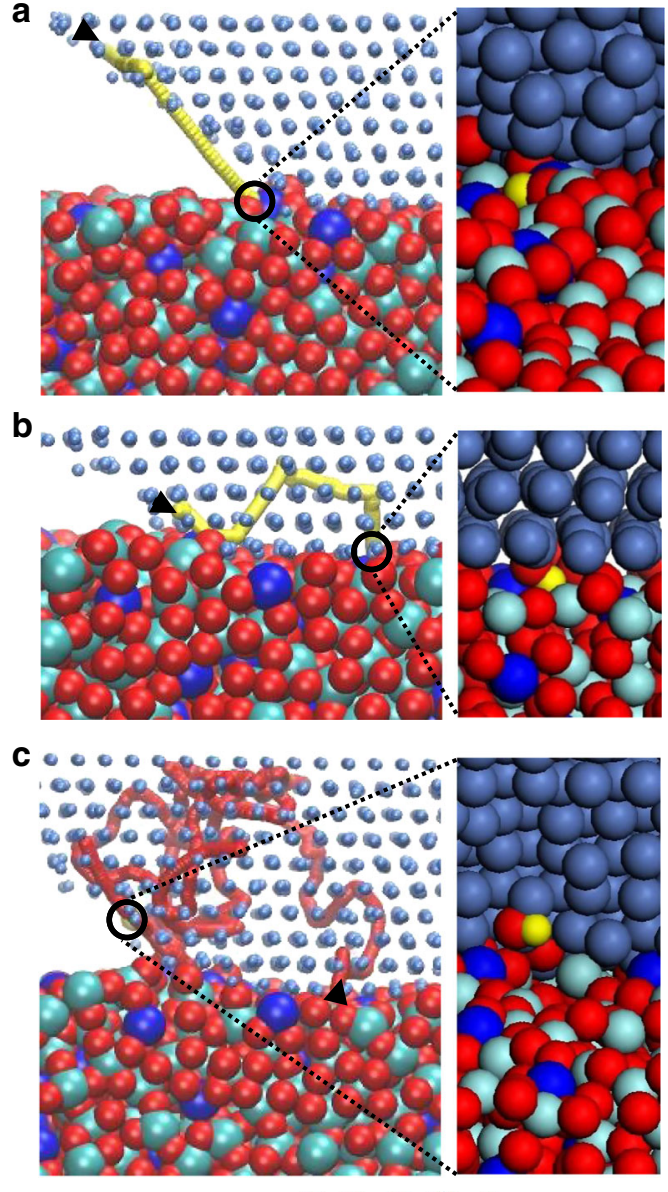

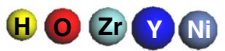

Fig. 5 Reaction dynamics simulations for triple phase boundary-1. a Hydrogen oxidation reaction (HOR)-I pathway. b HOR-II pathway. The trajectory of hydrogen $(\mathrm{H})$ starts from the arrow, and the circle denotes the final position where $\mathrm{OH}$ species is formed after a simulation period of 700 ps. The local environment near the formed $\mathrm{OH}$ species is presented in the magnified image, which is linked to the circle by dotted lines. c HOR-III pathway. A trajectory of oxygen $(\mathrm{O})$ starts from the arrow, and the circle denotes the final position where $\mathrm{OH}$ species is formed after a simulation period of $700 \mathrm{ps}$. The local environment near the formed $\mathrm{OH}$ species is presented in the magnified image, which is linked to the circle by dotted lines. Trajectories are shown along the Ni[110] and YSZ[001] directions

This pathway was labeled as HOR-II (Fig. 5b), which has been discussed theoretically by Weng et al. ${ }^{52}$. They concluded that a barrier of $0.89 \mathrm{eV}$ needs to be overcome for $\mathrm{H}$ diffusion through the Ni bulk, while the surface diffusion barrier is only $0.1 \mathrm{eV}$. Nevertheless, experiments have proved the enhanced $\mathrm{H}$ diffusion and absorption in Ni lattice at high temperatures ${ }^{53,54}$. Another pathway, which is referred to as HOR-III, is associated with $\mathrm{O}$ atom migration from YSZ to the $\mathrm{Ni}(220)$ surface through the $\mathrm{Ni}$ bulk to react with $\mathrm{H}$ on $\mathrm{Ni}$ surface to form $\mathrm{OH}$. A trajectory of $\mathrm{O}$ together with the snapshot of the formed $\mathrm{OH}$ is shown in Fig. $5 \mathrm{c}$. A series of snapshots with time for HOR-II and HOR-III are provided in Supplementary Fig. 14. To validate the determined ReaxFF parameters for $\mathrm{O}$ migration into the $\mathrm{Ni}$ bulk, we calculated the $\mathrm{NiO}$ formation energy to be $-0.8 \mathrm{eV}$, which is in reasonable agreement with the first-principles calculation result $(-1.0 \mathrm{eV})^{55}$. Besides, we did not observe $\mathrm{O}$ migration into the $\mathrm{Ni}$ bulk during optimization (see Supplementary Fig. 15). This result supports the fact that $\mathrm{O}$ migration in $\mathrm{Ni}$ can occur at certain two-
Table 2 Normalized average production of $\mathrm{OH}$

TPB-1 $\left(\AA^{-1}\right)$

TPB-2 $\left(\AA^{-1}\right)$

\begin{tabular}{llll}
\hline Model-1 & Model-2 & Model-3 & 0.0035
\end{tabular}

$\begin{array}{lll}0.0075 & 0.0041 & 0.0029\end{array}$

TPB triple phase boundary

phase interfaces like TPB-1 under high temperature (see Supplementary Fig. 16). Experimentally, O migration through the $\mathrm{Ni}$ bulk had been reported for $\mathrm{Ce}-\mathrm{Zr}$ oxide-supported $\mathrm{Ni}$ catalyst ${ }^{56}$.

For model-3, two $\mathrm{OH}$ species are formed. One of them is formed through the HOR-III pathway and remains on the $\mathrm{Ni}$ surface site. The other $\mathrm{OH}$, formed via HOR-I, is found to be 2.88 and $2.0 \AA$ away from the nearest $\mathrm{Ni}$ and $\mathrm{Zr}$, respectively.

In short, we observed three pathways for the formation of $\mathrm{OH}$ in HOR after the above simulations on TPB-1, namely, HOR-I (H diffusion on $\mathrm{Ni}$ surface toward TPB), HOR-II (H diffusion through Ni bulk to Ni/YSZ interface), and HOR-III (O migration from YSZ to Ni surface through bulk transfer).

For TPB-2 (Fig. 2b), the YSZ phase was not at the exact [001] zone axis. However, we adopted an ideal YSZ[001] model to represent the observed TPB structure for simplicity, and the model is presented in Supplementary Fig. 17. It should be noted that, owing to the high index (957) of the Ni surface, it is not worthy to increase the number of YSZ(020) layers toward the gas phase, as it may lead to improper contact between them at the TPB region. Therefore, we constructed only one model instead. After optimization, the $\mathrm{H}$ atom was located at the fcc site of $\mathrm{Ni}$ (111) surface. In this simulation, a single $\mathrm{OH}$ is formed through the HOR-I pathway. A trajectory of $\mathrm{H}$ is also shown in Supplementary Fig. 17. Note that the $\mathrm{OH}$ remains at TPB, having distances of 1.7 and $2.3 \AA$ from the nearest $\mathrm{Ni}$ and $\mathrm{Zr}$, respectively. The other two pathways (HOR-II and HOR-III) may also occur, because $\mathrm{O}$ and $\mathrm{H}$ migration into the $\mathrm{Ni}$ bulk is detected (Supplementary Fig. 18), indicating the relatively low activity of HOR through those processes compared to TPB-1.

In order to clarify the impact of the TPB structures as well as the different reaction pathways, we repeated all calculations six more times by changing the $\mathrm{H}$ positions on the Ni surface. The resulting time-averaged number of $\mathrm{OH}$ normalized by the TPB length is summarized in Table 2. It is calculated as $\left(\sum N_{\mathrm{OH}} \mathrm{d} t / t\right) / l$, where $N_{\mathrm{OH}}$ is the number of $\mathrm{OH}$ while $\mathrm{d} t, t$, and $l$ indicate the time step between frames, the total simulation time, and TPB length, respectively. The TPB lengths of TPB-1 and TPB-2 are 27.167 and $27.170 \AA$, respectively, which are almost the same. From TPB-1, the $\mathrm{OH}$ formations through the HOR-I pathway were found as nine, four, and five times during the simulations using model-1, model-2, and model-3, respectively. In addition, only one $\mathrm{OH}$ formation through the HOR-II pathway was observed in simulations using either model-1 or model-3, while model-2 exhibited three $\mathrm{OH}$ formations. Finally, the HOR-III pathway was not detected in model-1, whereas simulations using model-2 and model-3 displayed $\mathrm{OH}$ formation through the HOR-III pathway once and twice, respectively. By contrast, the TPB-2 simulations showed four and one $\mathrm{OH}$ formations via the HOR-I and HOR-III pathways, respectively. Therefore, our simulations indicate that TPB-1 was more active than TPB- 2 and that the activity at TPB-1 was influenced by the different interfacial distances between $\mathrm{Ni}$ and $\mathrm{O}$. The HOR-I pathway seems to be the easiest pathway regardless of the models, and this agrees well with many studies using DFT calulations $^{22,23,26}$. 
Apart from the HOR pathways observed in this study, an $\mathrm{O}$ spillover process, namely $\mathrm{O}$ migration from YSZ to Ni surface leading to the formation of $\mathrm{OH}$, was previously reported by using kinetic modeling method ${ }^{16,57,58}$. Later, this process was examined by Ammal et al. ${ }^{24}$ through DFT calculations and found to dominate over the $\mathrm{H}$ migration pathway. $\mathrm{Fu}$ et al. also investigated the $\mathrm{O}$ spillover process, coexisting with the $\mathrm{H}$ spillover process ${ }^{25}$. From our dynamics simulations, it can be concluded that the number of $\mathrm{O}$ migration was limited: for TPB-1 (model-1) four $\mathrm{O}$ atoms migrate, while only one $\mathrm{O}$ atom migrates during the simulation using TPB-2. Liu et al. also pointed out the importance of this process for the higher activity based on a kinetic study ${ }^{21}$. Therefore, it is indicated that the TPB-1 structure is favorable compared to TPB-2, while the relatively slow kinetics does not lead to the formation of $\mathrm{OH}$ species.

Finally, we did not observe $\mathrm{H}_{2} \mathrm{O}$ formation during the simulations. This may be due to the rate-limiting step of the $\mathrm{OH}+\mathrm{H}$ reaction, as well as the limited number of $\mathrm{H}$ atoms, the consumption of $\mathrm{H}$ atoms because of $\mathrm{OH}$ formation, or limited simulation time. DFT calulations ${ }^{22,23,26}$, ReaxFF-MD ${ }^{27}$, and kinetic modeling ${ }^{18}$ have concluded that $\mathrm{H}_{2} \mathrm{O}$ is formed near the TPB for HOR-I, while Goodwin et al. reported $\mathrm{H}_{2} \mathrm{O}$ formation on the Ni surface site ${ }^{19}$. In this study, MD simulations indicated that all pathways are possible for $\mathrm{H}_{2} \mathrm{O}$ formation.

\section{Discussion}

The motivation of this work is to understand the TPB on an atomic scale and simulate the HOR process on realistic models. First, we fabricated a conventional Ni/YSZ half-cell, and then we prepared high-quality TEM specimens through an FIB lift-out technique and moderate post-polishing. Finally, the TPB structures were observed by TEM and STEM, through which the visualization of the real atomic structure of TPB to the best of our knowledge is realized for the first time. Herein we demonstrated the existence of two TPB structures (TPB-1 and TPB-2), which are different from the structures assumed in the reported simulations. In TPB-1, Ni and YSZ formed a stable interface with an orientation of $\mathrm{Ni}[1 \overline{1} 0] / / \mathrm{YSZ}[001]$ and $\mathrm{Ni}(111) / / \mathrm{YSZ}(200)$, and the $\mathrm{Ni}(220)$ and $\mathrm{YSZ}(200)$ surfaces were open to the pore. Near TPB-2, the Ni/YSZ interface was $\mathrm{Ni}(957) / / \mathrm{YSZ}(200)$ while $\mathrm{Ni}$ (111) and YSZ(020) were exposed to the pore. In these two structures, the angle $\left(\theta_{\text {pore }}\right)$ between the $\mathrm{Ni}$ and YSZ surfaces was very different, being $35^{\circ}$ and $103^{\circ}$, respectively.

After constructing models based on these realistic structures, we carried out ReaxFF simulations. In order to obtain reliable simulation data, we began with extensive development of ReaxFF parameters for $\mathrm{Ni} / \mathrm{YSZ} / \mathrm{H}_{2}$ systems to clarify the HOR at TPB. Compared to the results of first-principles calculations, our developed ReaxFF parameters produced much smaller average energy deviations that are only about one third of those obtained from published ReaxFF parameters as shown in Table 1.

Using our own ReaxFF parameters and realistic models, three pathways for $\mathrm{OH}$ formation in HOR were observed during the reaction dynamics simulations: HOR-I (H diffusion on Ni surface toward TPB), HOR-II (H diffusion through Ni bulk to Ni/YSZ interface), and a new pathway HOR-III (O migration from YSZ to $\mathrm{Ni}$ surface through bulk transfer). Besides, the migration process of $\mathrm{H}$ and $\mathrm{O}$ was influenced by the TPB structures. The TPB-1 type structure was also found to be more active compared to TPB-2. Moreover, it was predicted that $\mathrm{H}_{2} \mathrm{O}$ may form at distinct sites on account of the $\mathrm{OH}$ back-transfer process. Our simulation results on the three models of TPB-1 and one model of TPB-2 indicate that the HOR pathway depends on many factors around the TPB, and it could be tuned by adjusting the local atomic structures. This finding agrees well with a recent study of dopant effect on HOR pathway, which changes with different cation dopants on $\mathrm{ZrO}_{2}{ }^{59}$. In addition, there are many more reports on surface pathways like HOR-I than on the bulk pathways including HOR-II and HOR-III observed in our simulation. Therefore, we propose that more studies should be carried out both theoretically and experimentally on the bulk pathways.

Finally, we would like to correlate our results to the anode performance and durability enhancement from three points of view. First, we found that HOR-1 pathway ( $\mathrm{H}$ diffusion on $\mathrm{Ni}$ surface toward TPB) seems to be the easiest one regardless of TPB structures. Hence, the performance can be enhanced by increasing the TPB length ${ }^{3,6}$. This is actually a well-known fact and can be realized experimentally by adjusting the Ni/YSZ ratio, $\mathrm{Ni}$ grain refinement, $\mathrm{Ni}$ infiltration, and so on as long as the mechanical robustness is well maintained. Second, we observed a new pathway (HOR-III) that proceeds via the diffusion of O in the bulk Ni. During this process, $\mathrm{Ni}$ may be partially oxidized, especially under high fuel utilization conditions, which will lead to performance degradation and mechanical disruption. Therefore, care must be taken to ensure mild operation parameters. Dopants could also be added into Ni/YSZ cermet to suppress the Ni oxidation $^{60}$. Third, we concluded that TPB- 1 type has higher activity toward HOR than TPB-2 type. The TPB-1 type was also more often observed in our TEM analysis, and it represents Ni standing on a flat YSZ substrate at TPB with very stable interface. Hence, the performance and durability are supposed to be improved if more TPBs of TPB-1 type exist, which could be achieved by reducing the particle size ratio of $\mathrm{Ni}(\mathrm{O}) / \mathrm{YSZ}^{61}$ and enhancing the thermal treatment under the condition of avoiding excessive $\mathrm{Ni}$ coarsening. However, those motions should be considered globally because the anode performance is a comprehensive output of various factors.

\section{Methods}

Cell preparation. A YSZ ( $8 \mathrm{~mol} \%$ yttria stabilized zirconia) electrolyte-supported half-cell was fabricated in a conventional way. First, NiO and YSZ with a weight ratio of 55:45 were ball-milled in ethanol. After drying the ethanol, the NiO/YSZ powder was grinded with $8 \mathrm{wt} . \%$ ethyl cellulose and $\alpha$-terpineol solvent to make the slurry, which was then screen-printed onto the YSZ electrolyte support (thickness $=1 \mathrm{~mm}$ ). The half cell was sintered at $1400^{\circ} \mathrm{C}$ for $3 \mathrm{~h}$. Finally, the reduction of $\mathrm{NiO}$ was carried out in humid $\mathrm{H}_{2}\left(2 \% \mathrm{H}_{2} \mathrm{O}\right)$ at $800{ }^{\circ} \mathrm{C}$ for $2 \mathrm{~h}$.

TEM specimen preparation and atomic structure observation. The pores of the porous electrode were first infiltrated by epoxy resin under vacuum in a CitoVac (Struers) system, so that the bulk cell could be readily handled in the next step. TEM specimen lift-out was performed using an FIB-SEM (HITACHI MI4000L) instrument. The specimen polishing was performed while the FIB voltage decreased from 30 to $3 \mathrm{kV}$. To remove the damaged/amorphous layers on the two sides of the specimen as much as possible, final polishing was carried out in an $\mathrm{Ar}$ ion milling machine (NanoMill Model 1040, Fischione) with a cold stage $\left(-165^{\circ} \mathrm{C}\right)$ at voltages between 0.6 and $1 \mathrm{kV}$. Structure observation at different scales was performed with JEOL JEM3200FSK (TEM and STEM modes, $300 \mathrm{kV}$ ) and JEOL JEM-ARM200F (TEM and STEM modes, $200 \mathrm{kV}$ ). Both machines were equipped with energy-dispersive X-ray spectroscopy detectors for elemental analysis.

TEM image simulation. STEM image simulations were performed using the QSTEM software (V2.22) ${ }^{50}$ based on the multislice method with the experimental parameters used in the JEOL ARM200F. The following electron beam parameters were employed: acceleration voltage $=200 \mathrm{kV}$, chromatic aberration $C_{\mathrm{C}}=1.6 \mathrm{~mm}$, spherical aberration $C_{\mathrm{S}}=0.0011 \mathrm{~mm}$, fifth-order spherical aberration $\mathrm{C} 5=1.756$ $\mathrm{mm}$, convergence angle $\alpha=24 \mathrm{mrad}$, and high-angle annular dark-field-STEM detector acceptance semi-angle of 90-370 mrad. During the microscope operation, the two-fold astigmatism and focus were continuously adjusted by the user and can be identified manually from the live imaging and fast Fourier transforms of the live image. However, in the simulations the two-fold astigmatism and high-order aberrations were neglected. 
Force field theory. The ReaxFF ${ }^{62}$ is based on the concept of bond order (BO), which is calculated according to the following equation:

$$
\begin{aligned}
\mathrm{BO}_{i j}^{\prime}= & \mathrm{BO}_{i j}^{\sigma}+\mathrm{BO}_{i j}^{\pi}+\mathrm{BO}_{i j}^{\pi \pi} \\
= & \exp \left[p_{\mathrm{bo} 1}\left(\frac{r_{i j}}{r_{0}^{j}}\right)^{p_{\mathrm{bo} 2}}\right]+\exp \left[p_{\mathrm{bo} 3}\left(\frac{r_{i j}}{r_{0}^{\pi}}\right)^{p_{\mathrm{bo} 4}}\right] \\
& +\exp \left[p_{\mathrm{bo5}}\left(\frac{r_{i j}}{r_{0}^{\pi \pi}}\right)^{p_{\mathrm{bo6}}}\right],
\end{aligned}
$$

where $r_{0}^{\sigma}, r_{0}^{\pi}$, and $r_{0}^{\pi \pi}$ are respectively the single, double, and triple bonds as a function of interatomic distances $r_{i j}$. $p_{\mathrm{bo} 1}, p_{\mathrm{bo} 2}, p_{\mathrm{bo} 3}, p_{\mathrm{bo} 4}, p_{\mathrm{bo} 5}$, and $p_{\mathrm{bo} 6}$ are parameters of the ReaxFF.

The total system energy consists of several partial energy terms that depend on the $\mathrm{BOs}$, such as the bond energy ( $\left.E_{\mathrm{bond}}\right)$ which in ReaxFF is given as:

$$
E_{\text {bond }}=-D_{\mathrm{e}}^{\sigma} \mathrm{BO}_{i j}^{\sigma} \exp \left[p_{\text {bel }}\left(1-\left(\mathrm{BO}_{i j}^{\sigma}\right)^{p_{\text {be2 }}}\right)\right]-D_{\mathrm{e}}^{\pi} \mathrm{BO}_{i j}^{\pi}-D_{\mathrm{e}}^{\pi \pi} \mathrm{BO}_{i j}^{\pi \pi},
$$

where $D_{\mathrm{e}}$ is the dissociation energy for each bond type. $p_{\mathrm{bel}}$ and $p_{\mathrm{be} 2}$ are parameters of the ReaxFF.

Besides $E_{\text {bond }}$, other contributors to the total energy include: the lone pair electrons, under- and over-coordination terms, valence angle energy, torsion energy terms, as well as van der Waals (vdW) and Coulomb interactions, which do not depend on the BOs. Details of the force field can be found elsewhere ${ }^{62,63}$. For the interactions of $\mathrm{H}-\mathrm{O}-\mathrm{H}, \mathrm{YSZ}-\mathrm{H}_{2}, \mathrm{Ni}-\mathrm{H}_{2}, \mathrm{Ni}-\mathrm{H}, \mathrm{Ni}-\mathrm{YSZ}$, and O-O, we developed a new set of ReaxFF for the atomic, bonding, off-diagonal (used to describe $\mathrm{BO}$ and $\mathrm{vdW}$ pair interactions $)^{46}$, and angle parameters. All these parameters are included in Supplementary Data 1.

Quantum mechanical calculations. In order to fit the ReaxFF parameters, QM calculations were performed using the first-principles DFT method implemented in the VASP code ${ }^{64,65}$. The exchange-correlation interactions were described by the Perdew-Burke-Ernzerhof functional. Spin-polarized calculations were applied throughout. To describe the electron-ion interactions, the projector augmented wave method was adopted. The cutoff energy of the plane wave basis set was 400 $\mathrm{eV}$. The electronic tolerance for a self-consistent loop and the energy tolerance for the ionic relaxation were $1 \times 10^{-6}$ and $1 \times 10^{-5} \mathrm{eV} /$ atom, respectively. The nudged elastic band calculation has been described elsewhere ${ }^{21}$.

Fitting procedure. To fit the ReaxFF potential, we utilized the algorithm described in POTFIT ${ }^{48}$. The target function for minimization is based on the deviation between the calculated ReaxFF values and DFT reference values with the following equation:

$$
Z(\alpha)=w_{\mathrm{e}} \sum_{i=1}^{n} u_{\mathrm{k}}\left(E_{\mathrm{ReaxFF}, i}(\alpha)-E_{\mathrm{FP}, i}\right)^{2}+w_{\mathrm{s}} Z_{\mathrm{s}}+Z_{\mathrm{F}},
$$

where $n$ is the number of configuration structures, $E_{\mathrm{FP}, i}$ is the reference values (such as energies) from first-principles DFT calculation, $E_{\mathrm{ReaxFF}, i}(\alpha)$ is the calculated ReaxFF values on the $i$ th structure after parametrization by $\alpha ; w_{\mathrm{e}}$ and $u_{\mathrm{k}}$ are the global and individual structural weights for the energy; and $Z_{\mathrm{s}}, Z_{\mathrm{F}}$, and $w_{\mathrm{s}}$ indicate the stress, the force, and the global weights for the stress, respectively. In our fitting, $w_{\mathrm{s}} Z_{\mathrm{s}}$ was neglected. For $\mathrm{Ni} / \mathrm{YSZ} / \mathrm{H}_{2}$ systems, we have fitted 69 parameters to improve the $\mathrm{H}-\mathrm{O}-\mathrm{H}, \mathrm{YSZ}-\mathrm{H}_{2}, \mathrm{Ni}-\mathrm{H}_{2}, \mathrm{Ni}-\mathrm{H}, \mathrm{Ni}-\mathrm{YSZ}$, and O-O interaction energies plus 24 energies for the HOR.

MD and mechanics simulations. First, models were built by using the lattice distances observed in the experiment (see Fig. 4). Then they were allowed to change due to the lattice expansion of $\mathrm{Ni}$ and YSZ in the course of isobaric-isothermal simulation at a temperature of $1073 \mathrm{~K}$ and a pressure of $1 \mathrm{~atm}$. The main reaction dynamics was calculated under the canonical ensemble corresponding to the constant volume and temperature condition. The temperature and pressure were controlled with the Nose-Hoover thermostat ${ }^{66}$ and barostat ${ }^{67}$, respectively.

The lattice parameters of two heterogeneous phases usually cannot perfectly match. Therefore, to obtain a well-matched Ni/YSZ interface, we expanded or compressed (for TPB-1 and TPB-2, respectively) the softer nickel crystal according to the misfit as calculated in Eq. (4):

$$
\text { Misfit }=\frac{m * a_{\mathrm{Ni}}-n * a_{\mathrm{YSZ}}}{n * a_{\mathrm{YSZ}}}
$$

where $n$ and $m$ are the number of unit cells for YSZ and Ni, respectively, and $a$ is the plane lattice parameter. The misfit was minimized down to $3 \%$. We used periodic boundary conditions to simulate an infinite horizontal surface. Because the simulation box length along the $z$ axis was long, the periodicity in the $z$ direction was virtually removed. We ran the MD trajectory for $700 \mathrm{ps}$. To optimize the TPB structures, we employed the FIRE method ${ }^{68}$. All MD and energy minimization calculations were carried out with USER-REAXC package ${ }^{69}$ as implemented in the LAMMPS code ${ }^{49}$.

\section{Data availability}

The data that support the findings of this study are available within the paper and its Supplementary Information and Data. Other relevant data are available from the corresponding authors upon reasonable request.

Received: 14 November 2018 Accepted: 20 March 2019

Published online: 23 April 2019

\section{References}

1. Wachsman, E. D. \& Lee, K. T. Lowering the temperature of solid oxide fuel cells. Science 334, 935-939 (2011).

2. Atkinson, A. et al. Advanced anodes for high-temperature fuel cells. Nat. Mater. 3, 17-27 (2004).

3. Wilson, J. R. et al. Three-dimensional reconstruction of a solid-oxide fuel-cell anode. Nat. Mater. 5, 541-544 (2006).

4. Iwai, H. et al. Quantification of SOFC anode microstructure based on dual beam FIB-SEM technique. J. Power Sources 195, 955-961 (2010).

5. Cronin, J. S., Wilson, J. R. \& Barnett, S. A. Impact of pore microstructure evolution on polarization resistance of Ni-Yttria-stabilized zirconia fuel cell anodes. J. Power Sources 196, 2640-2643 (2011).

6. Viveta, N. et al. Effect of Ni content in SOFC Ni-YSZ cermets: A threedimensional study by FIB-SEM tomography. J. Power Sources 196, 9989-9997 (2011).

7. Kenjo, T., Osawa, S. \& Fujikawa, K. High temperature air cathodes containing ion conductive oxides. J. Electrochem. Soc. 138, 349-355 (1991).

8. Joshi, A. S., Grew, K. N., Peracchio, A. A. \& Chiu, W. K. S. Lattice Boltzmann modeling of 2D gas transport in a solid oxide fuel cell anode. J. Power Sources 164, 631-638 (2007).

9. Suzue, Y., Shikazono, N. \& Kasagi, N. Micro modeling of solid oxide fuel cell anode based on stochastic reconstruction. J. Power Sources 184, 52-59 (2008).

10. Chen, H.-Y. et al. Simulation of coarsening in three-phase solid oxide fuel cell anodes. J. Power Sources 196, 1333-1337 (2011).

11. Irvine, J. T. S. et al. Evolution of the electrochemical interface in hightemperature fuel cells and electrolysers. Nat. Energy 1, 15014 (2016).

12. Mizusaki, J. et al. Kinetic studies of the reaction at the nickel pattern electrode on YSZ in $\mathrm{H}_{2}-\mathrm{H}_{2} \mathrm{O}$ atmospheres. Solid State Ion. 70/71, 52-58 (1994).

13. Bieberle, A., Meier, L. P. \& Gauckler, L. J. The electrochemistry of Ni pattern anodes used as solid oxide fuel cell model electrodes. J. Electrochem. Soc. 148, A646-A656 (2001).

14. Utz, A., Störmer, H., Leonide, A., Weber, A. \& Ivers-Tiffée, E. Degradation and relaxation effects of $\mathrm{Ni}$ patterned anodes in $\mathrm{H}_{2}-\mathrm{H}_{2} \mathrm{O}$ atmosphere. J. Electrochem. Soc. 157, B920-B930 (2010).

15. Yao, W. \& Croiset, E. Stability and electrochemical performance of Ni/YSZ pattern anodes in $\mathrm{H}_{2} / \mathrm{H}_{2} \mathrm{O}$ atmosphere. Can. J. Chem. Eng. 93, 2157-2167 (2015).

16. Bieberle, A. \& Gauckler, L. J. State-space modeling of the anodic SOFC system $\mathrm{Ni}, \mathrm{H}_{2}-\mathrm{H}_{2} \mathrm{O} \mid \mathrm{YSZ}$. Solid State Ion. 146, 23-41 (2002).

17. Bessler, W. G., Gewies, S. \& Vogler, M. A new framework for physically based modeling of solid oxide fuel cells. Electrochim. Acta 53, 1782-1800 (2007).

18. Vogler, M., Bieberle-Hütter, A., Gauckler, L., Warnatz, J. \& Bessler, W. G. Modelling study of surface reactions, diffusion, and spillover at a Ni/YSZ patterned anode. J. Electrochem. Soc. 156, B663-B672 (2009).

19. Goodwin, D. G., Zhu, H. Y., Colclasure, A. M. \& Kee, R. J. Modeling electrochemical oxidation of hydrogen on Ni-YSZ pattern anodes. $J$. Electrochem. Soc. 156, B1004-B1021 (2009).

20. Grew, K. N. \& Chiu, W. K. S. A review of modeling and simulation techniques across the length scales for the solid oxide fuel cell. J. Power Sources 199, 1-13 (2012).

21. Liu, S. et al. Predictive microkinetic model for solid oxide fuel cell patterned anode: Based on extensive literature survey and exhaustive simulations. J. Phys. Chem. C 121, 19069-19079 (2017).

22. Shishkin, M. \& Ziegler, T. Hydrogen oxidation at the Ni/yttria-stabilized zirconia interface: a study based on density functional theory. J. Phys. Chem. C 114, 11209-11214 (2010)

23. Cucinotta, C. S., Bernasconi, M. \& Parrinello, M. Hydrogen oxidation reaction at the Ni/YSZ anode of solid oxide fuel cells from first principles. Phys. Rev. Lett. 107, 206103 (2011).

24. Ammal, S. C. \& Heyden, A. Combined DFT and microkinetic modeling study of hydrogen oxidation at the Ni/YSZ anode of solid oxide fuel cells. J. Phys. Chem. Lett. 3, 2767-2772 (2012).

25. Fu, Z., Wang, M., Zuo, P., Yang, Z. \& Wu, R. Importance of oxygen spillover for fuel oxidation on Ni/YSZ anodes in solid oxide fuel cells. Phys. Chem. Chem. Phys. 16, 8536-8540 (2014).

26. Liu, S., Ishimoto, T., Monder, D. S. \& Koyama, M. First-principles study of oxygen transfer and hydrogen oxidation processes at the Ni-YSZ-gas triple 
phase boundaries in a solid oxide fuel cell anode. J. Phys. Chem. C 119, 27603-27608 (2015).

27. Merinov, B. V., Mueller, J. E., van Duin, A. C. T., An, Q. \& Goddard, W. A. III. ReaxFF reactive force-field modeling of the triple-phase boundary in a solid oxide fuel cell. J. Phys. Chem. Lett. 5, 4039-4043 (2014).

28. Helveg, S. et al. Atomic-scale imaging of carbon nanofibre growth. Nature 427, 426-429 (2004)

29. Cargnello, M. et al. Control of metal nanocrystal size reveals metal-support interface role for ceria catalysts. Science 341, 771-773 (2013).

30. Daio, T. et al. Lattice strain mapping of platinum nanoparticles on carbon and $\mathrm{SnO}_{2}$ supports. Sci. Rep. 5, 13126 (2015).

31. Akita, T., Maeda, Y. \& Kohyama, M. Low-temperature CO oxidation properties and TEM/STEM observation of $\mathrm{Au} / \gamma-\mathrm{Fe}_{2} \mathrm{O}_{3}$ catalysts. J. Catal. 324, 127-132 (2015).

32. Bassim, N. D. et al. Minimizing damage during FIB sample preparation of soft materials. J. Microsc. 245, 288-301 (2012).

33. Dickey, E. C., Fan, X. \& Pennycook, S. J. Direct atomic-scale imaging of ceramic interfaces. Acta Mater. 47, 4061-4068 (1999).

34. Dickey, E. C. et al. Preferred crystallographic orientation relationships of nickel films deposited on (100) cubic-zirconia substrates. Thin Solid Films 372, 37-44 (2000).

35. Beltrán, J. I., Gallego, S., Cerdá, J., Moya, J. S. \& Muñoz, M. C. Bond formation at the $\mathrm{Ni} / \mathrm{ZrO}_{2}$ interface. Phys. Rev. B 68, 075401 (2003).

36. Nahor, H. \& Kaplan, W. D. Structure of the equilibrated Ni(111)-YSZ(111) solid-solid interface. J. Am. Ceram. Soc. 99, 1064-1070 (2015).

37. Liu, S.-S., Jiao, Z., Shikazono, N., Matsumura, S. \& Koyama, M. Observation of the Ni/YSZ interface in a conventional SOFC. J. Electrochem. Soc. 162, F750-F754 (2015)

38. Liu, S.-S., Takayama, A., Matsumura, S. \& Koyama, M. Image contrast enhancement of $\mathrm{Ni} / \mathrm{YSZ}$ anode during the slice-and-view process in FIB-SEM. J. Microsc. 261, 326-332 (2016).

39. Mitome, M. Ultrathin specimen preparation by a low-energy Ar-ion milling method. Microscopy 62, 321-326 (2013).

40. Nelson, G. J. et al. Three-dimensional microstructural changes in the Ni-YSZ solid oxide fuel cell anode during operation. Acta Mater. 60, 3491-3500 (2012).

41. Dravid, V. P., Lyman, C. E., Notis, M. R. \& Revcolevschi, A. High resolution transmission electron microscopy of interphase interfaces in $\mathrm{NiO}-\mathrm{ZrO}_{2}$ (CaO). Ultramicroscopy 29, 60-70 (1989).

42. Dickey, E. C. et al. Structure and bonding at $\mathrm{Ni}-\mathrm{ZrO}_{2}$ (cubic) interfaces formed by the reduction of a $\mathrm{NiO}-\mathrm{ZrO}_{2}$ (cubic) composite. Microsc. Microanal. 3, 443-450 (1997).

43. Vellinga, W. P. \& Hosson, J. T. M. D. Atomic structure and orientation relations of interfaces between Ag and ZnO. Acta Mater. 45, 933-950 (1997).

44. Zhang, Z. et al. The peculiarity of the metal-ceramic interface. Sci. Rep. 5, 11460 (2015)

45. Kato, N. I. Reducing focused ion beam damage to transmission electron microscopy samples. J. Electron Microsc. 53, 451-458 (2004)

46. Mueller, J. E., van Duin, A. C. T. \& Goddard, W. A. Development and validation of ReaxFF reactive force field for hydrocarbon chemistry catalyzed by nickel. J. Phys. Chem. C 114, 4939-4949 (2010).

47. van Duin, A. C. T., Merinov, B. V., Jang, S. S. \& Goddard, W. A. III ReaxFF reactive force field for solid oxide fuel cell systems with application to oxygen ion transport in yttria-stabilized zirconia. J. Phys. Chem. A 112, 3133-3140 (2008).

48. Brommer, P. \& Gähler, F. Potfit: effective potentials from ab-initio data. Model. Simul. Mater. Sci. Eng. 15, 295-304 (2007).

49. Plimpton, S. Fast parallel algorithms for short-range molecular dynamics. J. Comput. Phys. 117, 1-19 (1995).

50. Koch, C. Determination of Core Structure Periodicity and Point Defect Density along Dislocations. PhD thesis, Arizona State Univ. (2002).

51. Blaylock, D. W., Ogura, T., Green, W. H. \& Beran, G. J. O. Computational investigation of thermochemistry and kinetics of steam methane reforming on $\mathrm{Ni}(111)$ under realistic conditions. J. Phys. Chem. C 113, 4898-4908 (2009).

52. Weng, M. H. et al. Kinetics and mechanisms for the adsorption, dissociation, and diffusion of hydrogen in $\mathrm{Ni}$ and Ni/YSZ slabs: a DFT study. Langmuir 28, 5596-5605 (2012).

53. Louthan, M. R. Jr., Donovan, J. A. \& Caskey, G. R. Jr. Hydrogen diffusion and trapping in nickel. Acta Met. 23, 745-749 (1975).

54. Wayman, M. L. \& Weatherly, G. C. The H-Ni (hydrogen-nickel) system. J. Phase Equilib. 10, 569-580 (1989).

55. Yu, J., Rosso, K. M. \& Bruemmer, S. M. Charge and transport in $\mathrm{NiO}$ and aspects of Ni oxidation from first principles. J. Phys. Chem. C 116, 1948-1954 (2012).

56. Hoang, T. M. C., Geerdink, B., Sturm, J. M., Lefferts, L. \& Seshan, K. Steam reforming of acetic acid - a major component in the volatiles formed during gasification of humin. Appl. Catal. B Environ. 163, 74-82 (2015).

57. Rossmeisl, J. \& Bessler, W. G. Trends in catalytic activity for SOFC anode materials. Solid State Ion. 178, 1694-1700 (2008)
58. Bessler, W. G. A new computational approach for SOFC impedance from detailed electrochemical reaction-diffusion models. Solid State Ion. 176, 997-1011 (2005).

59. Iskandarov, A. M. \& Tada, T. Dopant driven tuning of the hydrogen oxidation mechanism at the pore/nickel/zirconia triple phase boundary. Phys. Chem. Chem. Phys. 20, 12574-12588 (2018).

60. Welander, M. M., Zachariasen, M. S., Hunt, C. D., Sofie, S. W. \& Walker, R. A. Operando studies of redox resilience in ALT enhanced NiO-YSZ SOFC anodes. J. Electrochem. Soc. 165, F152-F157 (2018).

61. Prakash, B. S., Kumar, S. S. \& Aruna, S. T. Properties and development of Ni/ YSZ as an anode material in solid oxide fuel cell: a review. Renew. Sust. Energy Rev. 36, 149-179 (2014)

62. van Duin, A. C. T., Dasgupta, S., Lorant, F. \& Goddard, W. A. III ReaxFF: a reactive force field for hydrocarbons. J. Phys. Chem. A 105, 9396-9409 (2001).

63. Senftle, T. P. et al. The ReaxFF reactive force-field: development, applications and future directions. Npj Comput. Mater. 2, 15011 (2016).

64. Kresse, G. \& Furthmüller, J. Efficient iterative schemes for ab initio totalenergy calculations using a plane-wave basis set. Phys. Rev. B 54, 11169 (1996).

65. Kresse, G. \& Furthmüller, J. Efficiency of ab-initio total energy calculations for metals and semiconductors using a plane-wave basis set. Comput. Mater. Sci. 6, 15-50 (1996).

66. Hoover, W. G. Canonical dynamics: equilibrium phase-space distributions. Phys. Rev. A 31, 1695 (1985).

67. Hoover, W. G. Constant-pressure equations of motion. Phys. Rev. A 34, 2499 (1986).

68. Bitzek, E., Koskinen, P., Gahler, F., Moseler, M. \& Gumbsch, P. Structural relaxation made simple. Phys. Rev. Lett. 97, 170201 (2006).

69. Aktulga, H. M., Fogarty, J. C., Pandit, S. A. \& Grama, A. Y. Parallel reactive molecular dynamics: numerical methods and algorithmic techniques. Parallel Comput. 38, 245-259 (2012).

\section{Acknowledgements}

This work was supported by JST-CREST (JPMJCR11C2). Activities of the INAMORI Frontier Research Center were supported by the KYOCERA Corporation. L.C.S. thanks Professor A.C.T. van Duin (Pennsylvania State University) and Dr. B.V. Merinov (California Institute of Technology) for sharing their ReaxFF parameters and fruitful discussion. L.C.S. also thanks Dr. S. Liu (Kyushu University) for providing the theoretical data

\section{Author contributions}

S.-S.L. prepared the sample and carried out the microscope operation. L.C.S. performed the parameterization of ReaxFF, computational simulations, and modeling. A.I. (currently on leave of absence from the Institute for Metals Superplasticity Problems of RAS Khalturin St. 39, Ufa, 450001, Russia) assisted the technical set-up of POTFIT, and T.I. aided the simulations. T.Y. assisted the TEM operation and QSTEM simulation. Y.U., S. M., and M.K. conceived and supervised the project. S.-S.L. and L.C.S. composed the manuscript and prepared the figures. All the authors discussed the results, commented, and revised the manuscript.

\section{Additional information}

Supplementary information accompanies this paper at https://doi.org/10.1038/s42004019-0148-x.

Competing interests: The authors declare no competing interests.

Reprints and permission information is available online at http://npg.nature.com/ reprintsandpermissions/

Publisher's note: Springer Nature remains neutral with regard to jurisdictional claims in published maps and institutional affiliations.

Open Access This article is licensed under a Creative Commons Attribution 4.0 International License, which permits use, sharing
adaptation, distribution and reproduction in any medium or format, as long as you give appropriate credit to the original author(s) and the source, provide a link to the Creative Commons license, and indicate if changes were made. The images or other third party material in this article are included in the article's Creative Commons license, unless indicated otherwise in a credit line to the material. If material is not included in the article's Creative Commons license and your intended use is not permitted by statutory regulation or exceeds the permitted use, you will need to obtain permission directly from the copyright holder. To view a copy of this license, visit http://creativecommons.org/ licenses/by/4.0/.

(c) The Author(s) 2019 